\title{
Refreshing methods: reflections and provocations
}

Article

Accepted Version

Larsen, S., Lobo, M. and Maddrell, A. (2020) Refreshing methods: reflections and provocations. Social \& Cultural Geography, 21 (9). pp. 1328-1337. ISSN 1470-1197 doi: https://doi.org/10.1080/14649365.2019.1697461 Available at https://centaur.reading.ac.uk/88625/

It is advisable to refer to the publisher's version if you intend to cite from the work. See Guidance on citing.

To link to this article DOI: http://dx.doi.org/10.1080/14649365.2019.1697461

Publisher: Taylor \& Francis

All outputs in CentAUR are protected by Intellectual Property Rights law, including copyright law. Copyright and IPR is retained by the creators or other copyright holders. Terms and conditions for use of this material are defined in the End User Agreement.

\section{www.reading.ac.uk/centaur}

\section{CentAUR}

Central Archive at the University of Reading

Reading's research outputs online 


\title{
Refreshing methods: reflections and provocations
}

\author{
Soren Larsen ${ }^{a}$, Michele Lobo ${ }^{b}$ and Avril Maddrell ${ }^{c}$ \\ ${ }^{a}$ Department of Geography, University of Missouri, 202 Stewart Hall, Columbia, MO 65211-6170, \\ USA; ${ }^{b}$ Faculty of Arts and Education, Centre for Citizenship and Immigration, Deakin University, \\ 221 Burwood Highway, BurwoodVictoria 3125, Australia; ${ }^{\circ}$ Department of Geography and \\ Environmental Science, The University of Reading, RG6 6AB, UK
}

(Received 11 November 2019; accepted 12 November 2019)

This virtual special issue of Social \& Cultural Geography is part of a series of retrospectives published in celebration of the journal's twentieth anniversary. This issue features a selection of eight previously published articles on method that, taken together, highlight key themes and developments in methodological work since the journal's inception in 2000. In this introduction, the editors introduce the featured articles and, engaging other notable publications in the journal, offer a framework for thinking about the twenty years of methodological work published in the pages of Social \& Cultural Geography. We explore how these articles speak to current methodological issues and debates before concluding with a set of provocations for future methodological work.

Keywords: method; ethnography; practice; mobility; GIS; fieldwork

\section{Introduction}

Social and cultural geographers are drawn to exploring how common worlds are performed through a range of methods that materialise encounters and entangle multiple body-space-times. The eight papers selected for this virtual special issue of Social and Cultural Geography highlight the varied and innovative methodologically-focused work found in the pages of this journal. Individually and as a collection, these papers speak to the significant contributions the journal has made to methodology in critical human geography and allied fields over the last twenty years. We adopt a thematic approach to highlight some of the key methods that have figured in these contributions by interrogating the given, unsettling binaries (e.g., animate/inanimate, life/non-life, subject/object, nature/culture, urban/rural), and opening new questions about the spatiality of social and cultural life.

This issue also highlights the ways in which social and cultural geographers play with methods, bringing performative, non- or more-than-representational, and other experimental theoretical frameworks to bear on the critical, embodied study of socio-spatial practice. Perhaps this is to be expected given that Social \& Cultural Geography takes pride in publishing the best theoretically informed empirical research in the field. The twenty-year anniversary of the journal provides a unique opportunity to reflect on how the methodological discussions in this journal have contributed to and expanded the epistemological, ontological and political possibilities of critical social research. However, whilst reflecting on the past twenty years allows us to appreciate the significance of those discussions and interventions, it also draws attention to some gaps and lacunae in the conversation which merit attention. At the end of our introduction, we issue a set of provocations intended to foster a methodological pluralism that works with-across-between ontological differences. In the first section, we discuss four broad, but not exhaustive, themes identified in the selected papers: the event; feeling and doing space; socio-technological worlds; and moving-with practices. These are neither definitive 
nor mutually exclusive, but provide a useful frame for reflecting on research methods explored within the journal and the practices within the wider subfield of social and cultural geographies.

\section{The event: Performing epistemic spaces}

Exploring and entangling different knowledge systems is a political and ethical practice that involves learning how to inhabit many worlds. Such research can be challenging and difficult when we seek to go beyond phenomenological experiences of the bounded human body, the privileged academic/western subject, and the reproduction of white mastery (Mahtani, 2014; Nakamura, 2014; Nayak, 2011; ToliaKelly, 2016). Experimenting with methods that are attentive to feelings, emotions, affects, and the vitality of material things is crucial if we are to grasp the co-composition of human and more-thanhuman difference within a 'decolonizing spatial politics' (Robertson, 2017, p. 178.).

Watson and Huntington (2008) use 'the event' as an entry point into this co-composition, focusing on diverse human and more-than-human actors in Alaska, USA. They illustrate how moose hunting with Koyukon Athabascans is a spiritual, ethical, and embodied practice that entangles western and Indigenous knowledge systems. Objects such as wooden-hulled boats and automatic rifles are entangled with the hunters and the moose, as well as 'stories, places and ancestors' (Watson \& Huntington, 2008, p. 259) within assemblages that enliven a visceral learning-writing experiment. Ultimately, this is a methodological experiment oriented toward learning and relearning how to listen to more-than-human worlds as well as modes of 'becoming-animal' (Watson \& Huntington, 2008, p. 260) through protocols of reciprocity and respect. In this way, Watson, a geographer who grew up in New Jersey and Huntington, a member of the Huslia band of Koyukon, decentre the authority of the academic voice through the practice of co-writing that intertwines theories and narratives from Indigenous and Western worlds. Deleuze-Guattarian thought, for example, facilitates the theorisation of the moose hunting event as an assemblage, whereby agency is widely distributed among a range of actors. But the exploration of the assemblage, which is a Western philosophical framework, is also expanded by adopting a narrative style that weaves in Koyukon knowledge systems and cultural protocols. Experimental methods in cross-ontological dialogue have emerged in other Indigenous-academic collaborations featured in this journal (e.g., Lloyd, Suchet-Pearson, Wright, \& Bururrwanga, 2010), and offer an important way forward in decolonising geography.

Entangling diverse ontologies also calls for experimental, more-than-representational, and participatory approaches that involve academics in responsibilities to and for Indigenous communities and lands well after a project's completion. The forthcoming special issue titled Living protocols: Remaking worlds in the face of extinction (Theriault, Leduc, Mitchell, Rubis, \& Gaehowako, 2019) draws attention to the need to produce collaborative knowledges that bring together Indigenous people, non-Indigenous scholars, elders, activists, artists and communities in responsible and caring relationships. Drawing on feminist, neomaterialist, decolonial and Indigenous geographies, the authors entangle land, ancestors, water, plants, animals and many other beings to challenge narratives of violence and extinction. Using alternative methodologies, they co-create 'bonds, protocols, laws and worlds' (Theriault et al., 2019, p. 6) through a range of practices that include listening, relearning, slowing down, concealing, healing and remaking. In this way, the authors animate contemporary political debates on encounter, recognition and resistance that call for feeling and doing space in new ways.

\section{Feeling and doing space: The field}

Difference, power relationships, the micropolitics of everyday encounters, and ethical dilemmas in the 'field' have always been central to the ways in which social and cultural problems are addressed in the journal (Basnet, Johnston, \& Longhurst, 2018; Fincher, 2011; Listerborn, 2015; Maillet, Mountz, \& Williams, 2017; Nagel \& Staeheli, 2008). Feminist geographers continue to draw attention to 
researcher-researched power relationships, the shifting nature of the field, the politics of personalacademic vulnerability, and the challenges as well as limits of critical self-reflexivity (Kobayashi, Preston, \& Murnaghan, 2011; Madge, 2016). Such work has been expanded through research on relational geographies of care with vulnerable and/or racialised peoples, including ethnic/ethnoreligious minority migrants, refugees and asylum seekers, LGBTQ communities, and the disabled. Qualitative techniques such as thick description, in-depth interviews, focus groups, collective biographies, and comic-book journals provide enriching insights into the politics as well as the poetics of the field (Katz, 2013). In this special issue, Meth and McClymont (2009) take this politics one step further by arguing that fieldwork is itself an identity negotiation that unfolds through methods within asymmetrical spaces of power and privilege. In their research with male experiences of violence in Durban, South Africa, they began to see how their own qualitative mixed-methods intersected with the marginalization of the twenty men involved in their study. This insight not only helped them contextualize findings and shape future research engagements, but also provided strategies for working in solidarity with the men to challenge their own marginalization. For Meth and McClymont (2009), feeling and doing the field in this way opens up a research politics with the 'capacity for positionalities to be renegotiated and for different spaces of disclosure to be created [which] services a progressive research aim to work against marginalization and to provide those who are marginalized with a voice to share their experiences' (p. 922). They conclude by calling for a critical debate on the politics of possibilities of qualitative mixed-methods work on gender identities and masculinities in particular, a call that was taken up later on in this journal, from a slightly different angle, in the 2017 special issue (volume 18(7)) on research with vulnerable groups.

Questions of personal and professional vulnerability are at the heart of Claire Madge's (2016) paper in which she uses a creative autobiographical approach in order to explore her own experience of, and living on after, breast cancer treatment. Madge integrates three creative pieces within her account, layering text and images whilst i) cataloguing a seemingly unremitting list of medical appointments; a reflection on the emotional-viscerally-charged place identity of the chemotherapy suite; and a trilogy of poems that capture something of the pain and hope of the experience of 'livingdying' with cancer. Madge 'storifies' her experience, using these creative methods as a form of self-reflective catharsis, giving the reader privileged access to her moving representations of deeply personal and challenging experiences. Drawing on personal knowledge and understanding she highlights important insights, such as the longer term, ongoing impact of cancer treatment on the body, emotions, work and finances. Yet, more than this, Madge uses her experience and these emotional-creative accounts to reflect on both the value and the cost of such work - its methodology and reception - within academic scholarship. A refreshingly honest expression of vulnerability regarding the reception of her creative pieces and personal narrative by an academic audience (a theme echoed by other authors in this journal in relation to sharing personal experiences, emotions and beliefs), is followed by an agenda for such research. This includes important methodological and epistemological points: the need to recognise that creative agency reflects shifting positionality and therefore has limits; the need for vulnerable autobiographical researcher self-care; and awareness of the vulnerabilities of others being researched in related work, which requires a prioritisation of careful, thoughtful and compassionate research practices. Implicit to these arguments is the need for careful, thoughtful and compassionate reading and responses to (auto)biographical work such as this, and more explicit than this, a call for politicised compassion for the ill, dying and grieving in care services and work places - including academia. Grounded in Feminist methods and theory, the autobiographical 'minded-body' approach also yields theoretical benefits, notably the value of 'precarious theorising' which challenges tidy and disembodied academic discourse.

A number of other related methods within the journal include analysis of autobiographical creative writing and carto-fiction (Peterle, 2018); art (Hawkins, 2010; McNally, 2018); oral histories, visual 
narratives, videographic experimentation (Paterson \& Glass, 2018); the 'deep mapping' of emotionalaffective topographies (Maddrell, 2016); and multisensory listening (Duffy \& Waitt, 2013) - all important approaches to 'feeling and doing' the field. The paper by Frances Morton (2005) explores Irish traditional music and uses ethnographic methods to gain access to the non- or more-thanrepresentational fleeting yet visceral space-times of musical performance. She employs the strategy of 'performing research in the now', which mimics the informal and speculative behaviour of musicians engaged in performance, to evoke multisensory spaces and times that cannot be repeated or retrieved. Morton's proposal for a 'performance ethnography' resonates today, almost fifteen years later, in its call for approaches that use performance to grasp the affects and atmospheres of lively geographies. This is an approach that can be seen in the growth of walk-along, cycling or dance interviews.

Other work in Social and Cultural Geography has focused on the 'field' as a place that materialises through embodied research and mobile methods (e.g., dressage, surfing, touring, freediving). David Crouch's (2001) paper, for example, focuses on the mobilising potential of everyday encounters and 'lay geographies' through creative methods of 'flirting' with space. Here, flirting is a romantic performance of being involved in space and transforming space through a body that is 'sensuous, sensitive, agentive and expressive in relation to the world' (Crouch 2001, p. 62). The world is felt and discovered through relationships that move beyond 'mental rationality' and are imaginative, free, playful, humorous, and poetic. Through an empirical focus on caravanning in Essex, South Yorkshire and Weardale, UK, Crouch argues that the field not only has semiotic significance for the subjects, but also broader 'anthropological, spatial and research-method significance' (Crouch, 2001, p. 63). He and his colleagues spent twelve weekends with holiday-makers had to employ novel methods in their desire to be respectful rather than intrusive. These involved 'hanging out' in spaces such as the pub, participating in conversations at barbecues, and going for walks and playing games with a diverse range of groups. The research-researched relationships varied and circulated feelings of safety but also threat, discomfort, and rage - the sensuous geographies through which the 'field' emerged and 'made sense' to participants and researchers in the study.

\section{Socio-technological worlds}

Social and cultural geographers have a longstanding interest in the socio-technological worlds illuminated by Science and Technology Studies (STS), Actor Network Theory (ANT), and cyberfeminism. Dixon and Whitehead (2008, p. 606) explore both old and new dialogues in geography and technology studies, arguing that technology has the capacity to transform and reorder 'the meat, bones, nerves, synapses not only of individual human bodies, but all manner of corporealities'. They call on geographers to adopt a 'research posture' rather than a rulebook in exploring socio-technological worlds. This involves re-skilling as well as improving competencies in deploying and triangulating both qualitative and quantitative methods. However, to be methodologically coherent and effective this is more complex than first sight; a research approach that simply 'mixes' methods can be seriously compromised if it is not attentive to and transparent about any 'incompatibilities, awkward silences and ontological ambiguities' (Dixon \& Whitehead, 2008, p. 610). This journal provides scope to expand research in this area, especially given the emergence of artificial intelligence, the 'crises' associated with the advent of the Anthropocene, deathscapes, urban natures, multispecies justice, and the desire for abundant futures. At the same time, it is imperative to ensure spaces for geographies of the margins, geographies of colour, and heed the voices of those people who inhabit 'emotionally toxic material spaces' and have the potential to contribute to the 'future of geographical thinking' (Mahtani, 2014, p. $360)$.

The journal has also provided space for the discussion of the methodological challenges and opportunities of using Geographical Information Systems (GIS) in the critical study of social-cultural geographies (Kwan, 2008). The analytical capabilities of GIS, for example, have rarely been used to 
visualise and quantify changes in the geography of languages. Luo, Hartmann, Liu, \& Huang (2007) integrate these quantitative techniques with qualitative reasoning to explore spatial patterns of Zhuang (Tai), the largest minority language spoken by indigenous Chinese people. They used GIS to explore linguistic and cultural interactions between Tai-speaking minorities and Han Chinese settlers. The paper highlighted the complex and dynamic process of 'sinification', or assimilation to Han culture, that is often enforced on Tai-speaking minorities who live in southern China. To provide context for exploring the spatial patterns between language and kinship, Luo et al. created GIS terrain models with river networks, possible migration routes, and transportation networks, and meshed these findings with analysis of the imperial policies of Han Chinese newcomers over time, from 214 BCE to the most recent interventionist policies of the Chinese Communist Party. Because kinship terms (mother, father) rather than pronouns are used in Tai and Chinese languages, the authors were able to analyse changes in these terms by county. They selected 45 kinship terms and, at thirty-six data sampling points, calculated kinship sinification scores for each county. In the next stage, they performed a regression analysis by using kinship terms as the dependent variable. The results showed high sinification scores near the coast and the international border with Vietnam, areas with gentle slopes close to major transportation hubs.

Equally interesting in this study, however, are the limitations of the data sample. Although the GIS analysis clearly revealed the settlement patterns of Zhuang in southern China as well as the complexity of cultural and linguistic changes following the arrival of the Han Chinese into the Zhuang region, it also produced 'surprising findings' 'unexpected outcomes' (Luo et al., 2007, p. 589) and other discrepancies - precisely those that Dixon and Whitehead (2008) enjoin geographers to address by mixing quantitative and qualitative methods. For example, the regression analysis did not support the hypothesis that sinification scores would be higher closer to rivers, where Han Chinese and Taispeaking people would have more opportunities for encounter. Qualitative reasoning was therefore necessary to analyse the results and explore the deeper structures of social, cultural, historical and political processes.

Socio-technological worlds are getting increasingly 'fleshy', calling for methods that think beyond the reduction of technology to inert materials while attending to the ways in which bodies and subjectivities are constituted through affective capacities of technology. In this issue, Waitt and Phillips (2016) use a material-visceral approach to explore the practices of refrigeration and ridding that transform food into waste. Changes in the appearance, texture, and smell of food elicit visceral responses that attune bodies to the agency of food as a material item with its own dynamism, power, and capacity. Drawing insights from feminism and food waste scholarship, the paper explores refrigeration and ridding practices, proficiencies, rhythms, and categorisations as everyday enactments that bring the affective and the sensorial together in the 'unmaking' of matter. Their methods included semi-structured interviews with 28 households in their kitchens, use of visual elements such as sketches and photos, and fridge inspections in Wollongong, Australia. Fridge biographies, photographs of the journeys of food contents, and embodied practices of storing food (e.g., moving, touching, sighting) all provided access to tacit understandings of food waste that often escape attention. Understanding these connections, interviewees in the study became more wary of generating food waste and were keen to become responsible and healthy citizens, suggesting methods that attend to 'gut' feelings and affective responses may generate new practices as well as scholarship on the 'problem' of food waste. This, we suggest, could also contribute to thinking within the Anthropocene (Tolia-Kelly, 2016), an epoch that gives lie to the notion of a coherent, hermetically sealed human subject whose body is a machine, and calls for methods that disclose instead the fleshy rhythms of more-than-human, socio-technological worlds.

\section{Mobilities: Moving-With Practices}


The rapid growth of interest in mobilities and practices over the past two decades reflects the burgeoning geographical engagement with non- or more-than-representational theories of landscape/landscaping, an engagement that began, in earnest, at the turn of the twenty-first century, around the time Social and Cultural Geography was launched. The journal has published abundant work associated with the "new mobilities paradigm', which drew attention to complex methodological problems involved in studying landscape as an emergent and relational practice. Such problems were front and centre in a panel discussion held in 2006 at the Royal Geographical Society (with the Institute of British Geographers) Annual Conference in London, which was published in volume 9(2) of this journal. In the introduction to that issue, Merriman et al. (2008) noted that the mobilities paradigm had, up to that time, drawn upon too narrow a range of methods in attempting to understand particular practices, mobilities, and landscapes. If landscape is understood as practice and through practice, then our methods of practice cannot be limited in scope, but must experiment with the many different modalities of landscape/landscaping.

In our selection for this issue, Hui (2013) argues that the problem in mobilities research is not just that the methods of practice are too narrow, but more problematically, the (often co-producing) relationship between practice and mobility is not clearly understood. Methodological integrity, she notes, is particularly important because nonrepresentational techniques tend to generate 'a potentially dizzying wealth of details' (Hui, 2013, p. 890), which seems to defy the inference of pattern and relation. Borrowing from the work of sociologist Andreas Reckwtiz, Hui offers praktik as both a unit of analysis and a theory of method that together chart the emergence of practices through the mobilities of heterogeneous elements engaged in contingent associations. Using case studies of patchwork quilting and bird-watching, praktik are conceptualized as 'sites of mobilities' through which practices unfold. So, for example, the practice of bird watching emerges through and in response to the mobilities of the birds, the affective currents of 'travelling-in-anticipation' and 'travelling-in-excitement or disappointment' (Hui, 2013, p. 896), and the circulation of bird lists, books, and ideas. Praktik trace the linked but discontinuous times, non-contiguous spaces, and object-oriented mobilities of practices-inthe-making, revealing how mobilities shape practices in, through, and as landscape/landscaping.

Hui's intervention points to methodological questions that remain salient in mobilities research, and which we echo here. First, how can we rethink the spatio-temporal boundaries of practice in terms of (dis)contiguous and (dis)continuous mobilities, including the intermittent and disjointed patterns of travel and movement that are key moments in landscape/landscaping? Second, how do we understand the rhythms of practice as constitutive of social groups and place, not just expressive of them? Finally, Hui's piece asks us how we might discern the materialities involved in 'moving-with' practices; in other words, how we might trace material and immaterial elements in a way that does not reify, the fundamental flaw of the representational approach? Moving forward, as it were, what are the methods for 'moving-with' practices in ways that grasp the co-emergent rhythms of landscape/landscaping? Rhythm is a methodological challenge that has attracted attention in varied studies such as those on retail, tourism and pilgrimage (e.g., Kärrholm, 2009; Sarmento, 2017), as well as the Lefebvriangrounded collection Geographies of Rhythm (Edensor 2010), which highlights spaces and practices of rhythm and arrhythmia, both of which merit further study.

\section{Provocations}

By way of closing, we summarise key attributes of the papers that make up this virtual special issue and look ahead to new methodological challenges, opportunities, and debates to be taken up in the journal's next twenty years.

The papers discussed above underscore that effective research methodologies in the field of social and cultural geography need to be:

a) Transparent and replicable 
b) Open to the possibilities of working with quantitative as well as qualitative data

c) Reflective and reflexive (especially aware of shifting contingencies and limitations of single and mixed methods)

d) Inclusive of body-minds, emotions, relations and experiences

e) Attentive to existing and emerging/ innovative links between methods and theory

f) Sensitive to the needs and vulnerabilities of participants (including self-care in autobiographical work)

g) Engage with opportunities to inform practice and policy where relevant

h) Prepared to address missing, marginalised or excluded communities and research questions that are of social and/or cultural relevance

Moving forward, we argue for more explicit engagement with social and cultural geography-relevant research methods in the journal, including those which use sources from art, literature and wider geohumanities to those using high tech body cams or big data. What matters is that the best - most appropriate and effective method is applied to understand and address current and emerging issues of cultural understanding, social policy and the politics of inclusion-exclusion-marginalisation. Over and above the methods discussed and signalled in this brief introduction we argue for social and cultural geography research methods which centre around decolonising, refreshing, and pluralising method.

This includes experimental methods that 'weave' disparate ontological styles into relational ways of knowing and being and in this way challenge colonial binaries - but decolonising methods are not strictly an Indigenous or postcolonial concern, as everyday gendered, classed and sexed experiences demonstrate. Engaging with geopoetics and speculation in knowledge production brings marginal, subaltern, and alternative epistemologies and modes of representation to the fore, viscerally and materially. Photographs (including archival images and photovoice), participatory video, documentary filmmaking, creative writing, art practice, oral histories, myths, songs - these and other alternative modes of representation have much potential to unsettle and decentre normative geography.

We have already mentioned the need to provide spaces for marginalized voices that add 'colour' to the Western academy, but this carries a number of risks that bear directly on methodological concerns. We urgently need methods that value and respect, rather than 'lust' after and appropriate, Indigenous and other non-Western knowledges, but we also need methods that allow these knowledges to stand in productive agonism with and against the Western academy. Such agonism does not necessarily entail conflict or opposition, but it is nonetheless an essential 'research posture' in unsettling and invigorating the academy - not only intellectually, but viscerally - and they raise important methodological questions. For instance, what are the ethical considerations when conducting research that uses words and concepts beyond the English language by scholars, including diasporic and Indigenous scholars, who aim to entangle diverse worlds? How do we participate in entanglements that do more than nourish our own academic ambitions? How do we negotiate all the entanglements we find ourselves in along the way? What are our responsibilities and obligations in these entanglements, and how do these shape our geographical practice?

Finally, we also call for refreshing methods, by which we mean constantly reinvigorating the methods we use in response to our entanglements in the atmospheres, memories, rhythms, materialities of places, spaces, and landscapes. Here we are inspired by the more-than representational approaches that 'refresh' knowledge production by estranging the ordinary and luring the antipodean - deathscapes, seascapes, the subterranean-reminding us that method is more a means of responding to the world than studying it. In this respect, we have ample opportunity to develop material-visceral methods that respond to proliferating entanglements with, among other things, biosensors, drones, multispecies worlds, virtual realities, bacteria, artificial intelligence, as well as online platforms and apps (e.g., Twitter, Instagram). Assembling methods that enable us to centre human and more-than-human 
difference in catastrophic worlds will also help us address the toxicity of identity politics, ultranationalism, white ethnonationalism, socio-economic disadvantage, climate change denial, and species mass extinction. This, we envision, both requires and results in a vibrant methodological pluralism that works across ontological, epistemological and political differences and relations, helping us think more critically and creatively with and for the spatialities that animate social and cultural life.

\section{References}

Basnet, S., Johnston, L., \& Longhurst, R. (2018). Embodying 'accidental ethnography': Staying overnight with former Bhutanese refugees in Aotearoa New Zealand. Social \& Cultural Geography, published online 1 June 2018, doi: 10.1080/14649365.2018.1480056.

Clark, N. (2014). Geo-politics and the disaster of the Anthropocene. Sociological Review, 62, 27-28.

Crouch, D. (2001). Spatialities and the feeling of doing. Social \& Cultural Geography, 2, 61-75.

Dixon, D. P. \& Whitehead, M. (2008). Technological trajectories: Old and new dialogues in geography and technology studies. Social \& Cultural Geography, 9, 601-611.

Duffy, M. \& Waitt, G. (2013). Home sounds: Experiential practices and performativities of hearing and listening. Social \& Cultural Geography, 14, 466-481.

Edensor, T. (2010). Geographies of rhythm: Nature, place, mobilities and bodies. Farnham, Surrey, England: Ashgate.

Fincher, R. (2011). Cosmopolitan or ethnically identified selves? Institutional expectations and the negotiated identities of international students. Social \& Cultural Geography, 12, 905-927.

Hawkins, H. (2010). Turn your trash into...rubbish, art and politics. Richard Wentworth's geographical imagination. Social \& Cultural Geography, 11, 805-827.

Hui, A. (2013). Moving with practices: The discontinuous, rhythmic and material mobilities of leisure. Social \& Cultural Geography, 14, 888-908.

Johnson, N. C. (2004). Fictional journeys: Paper landscapes, tourist trails and Dublin's literary texts. Social \& Cultural Geography, 5, 91-107.

Katz, C. (2013). Playing with fieldwork. Social \& Cultural Geography, 14, 762-772.

Kärrholm, M. (2009). To the rhythm of shopping - on synchronisation in urban landscapes of consumption. Social \& Cultural Geography, 10, 421-440.

Kobayashi, A., Valerie Preston, V., \& Murnaghan, A. (2011). Place, affect, and transnationalism through the voices of Hong Kong immigrants to Canada. Social \& Cultural Geography, 12, 871888.

Kwan, M. (2008). From oral histories to visual narratives: Re-presenting the post-September 11 experiences of the Muslim women in the USA. Social \& Cultural Geography, 9, 653-669.

Listerborn, L. (2015). Geographies of the veil: Violent encounters in urban public spaces in Malmö, Sweden. Social \& Cultural Geography, 16, 95-115.

Lloyd, K., Suchet-Pearson, S., Wright, S., \& Burarrwanga. L. (2010). Stories of crossings and connections from Bawaka, North East Arnhem Land, Australia. Social \& Cultural Geography, $11,701-717$.

Luo, W., Hartmann, J., Liu, J., \& Huang, P. (2007). Geographic patterns of Zhuang (Tai) kinship terms in Guangxi and border areas: A GIS analysis of language and culture change. Social \& Cultural Geography, 8, 575-596.

Maddrell, A. (2016). Mapping grief. A conceptual framework for understanding the spatial dimensions of bereavement, mourning and remembrance. Social \& Cultural Geography, 17, 166-188.

Madge, C. (2016). Living through, living with and living on from breast cancer in the UK: Creative cathartic methodologies, cancerous spaces and a politics of compassion. Social \& Cultural Geography, 17, 207-232. 
Mahtani, M. (2014). Toxic geographies: Absences in critical race thought and practice in social and cultural geography. Social \& Cultural Geography, 15, 359-367.

Maillet., P., Mountz, A., \& Williams, K. (2017). Researching migration and enforcement in obscured places: Practical, ethical and methodological challenges to fieldwork. Social \& Cultural Geography, 18, 927-950.

McNally, D. (2019). 'I am Tower of Hamlets': Enchanted encounters and the limit to art's connectivity. Social \& Cultural Geography, 20, 198-221.

Merriman, P., Revill, G., Cresswell, T., Lorimer, H., Matless, D., Rose, G., \& Wylie, J. (2008). Landscape, mobility, practice. Social \& Cultural Geography, 9, 191-212.

Meth, P., \& McClymont, K. (2009). Researching men: The politics and possibilities of a qualitative mixed-methods approach. Social \& Cultural Geography, 10, 909-925.

Morton, F. (2005). Performing ethnography: Irish traditional music sessions and new methodological spaces. Social \& Cultural Geography, 6, 661-676.

Nagel, C. R., \& Staeheli, L. (2008). Integration and the negotiation of 'here' and 'there': The case of British Arab activists. Social \& Cultural Geography, 9, 415-430.

Nakamura, N. (2014). What is a community's desire? A critical look at participatory research projects with Indigenous communities. Social \& Cultural Geography, 16, 165-182.

Nayak, A. (2011). Geography, race and emotions: Social and cultural intersections. Social \& Cultural Geography, 12, 548-562.

Peterle, G. (2018). Carto-fiction: Narrativising maps through creative writing. Social \& Cultural Geography, 20, 1070-1093.

Paterson, M., \& Glass, M. R. (2018). Seeing, feeling, and showing 'bodies-in-place': Exploring reflexivity and the multisensory body through videography. Social \& Cultural Geography, published online, 8 February 2018, doi: 10.1080/14649365.2018.1433866.

Robertson, S. (2016). Thinking of the land in that way': Indigenous sovereignty and the spatial politics of attentiveness at Skwelkwek'welt. Social \& Cultural Geography, 18, 178-200.

Sarmento, J. (2017). Tourists' walking rhythms: 'Doing' the Tunis Medina, Tunisia. Social \& Cultural Geography, 18, 295-314.

Theriault, N., Leduc, T., Mitchell, A., Rubis, J., \& Gaehowako, N. J. (2019). Living protocols: Remaking worlds in the face of extinction. Social \& Cultural Geography, published online, 23 May 2019, doi: 10.1080/14649365.2019.1619821.

Tolia-Kelly, D. P. (2016). Anthropocenic culturecide: An epitaph. Social \& Cultural Geography, 17, 786-792.

Waitt, G., \& Phillips, C. (2016). Food waste and domestic refrigeration: A visceral and material approach. Social \& Cultural Geography, 17, 359-379.

Watson, A., \& Huntington, O. H. (2008). They're here-I can feel them: The epistemic spaces of Indigenous and Western Knowledges. Social \& Cultural Geography, 9, 257-281. 